\title{
International Survey of Speech-Language Pathologists' Practices in Working with Children with Autism Spectrum Disorder
}

\author{
Gail Gillon $^{a}$ Yvette Hyter $^{\mathrm{b}}$ Fernanda Dreux Fernandes ${ }^{c}$ Sara Ferman ${ }^{d}$ \\ Yvette Hus $^{\mathrm{e}}$ Kakia Petinou $^{\mathrm{f}}$ Osnat Segald Tatjana Tumanovag \\ Ioannis Vogindroukas ${ }^{\mathrm{h}}$ Carol Westby ${ }^{i}$ Marleen Westerveld ${ }^{j}$ \\ a University of Canterbury, Christchurch, New Zealand; b'Western Michigan University, Kalamazoo, MI, USA; \\ 'University of São Paulo, São Paulo, Brazil; ${ }^{\mathrm{d}}$ Tel Aviv University, Tel Aviv, Israel; ${ }^{\mathrm{e}}$ TAV College, Montreal, QC, Canada; \\ ${ }^{f}$ Cyprus University of Technology, Limassol, Cyprus; ${ }^{9}$ Moscow State University of Education, Moscow, Russian Federation; \\ ${ }^{h}$ Research and Education Institute for Speech Therapy (IEEL), Thessaloniki, Greece; 'Bilingual Multicultural Services, \\ Albuquerque, NM, USA; ${ }^{j}$ Griffith University, Gold Coast, QLD, Australia
}

\section{Keywords}

Speech-language pathologists - Autism spectrum disorder . Survey · Assessment · Intervention · Diagnosis · Autism .

Children · Adolescents

\begin{abstract}
Objective: Autism spectrum disorder (ASD) is a complex neurodevelopmental impairment. To better understand the role of speech-language pathologists (SLPs) in different countries in supporting children with ASD, the International Association of Logopedics and Phoniatrics (IALP) Child Language Committee developed a survey for SLPs working with children or adolescents with ASD. Method and Participants: The survey comprised 58 questions about background information of respondents, characteristics of children with ASD, and the role of SLPs in diagnosis, assessment, and intervention practices. The survey was available in English, French, Russian, and Portuguese, and distributed online. Results: This paper provides a descriptive summary of the main findings from the quantitative data from the 1,114 SLPs (representing 35 countries) who were supporting children with ASD. Most of the respondents $(91 \%)$ were experienced in working with
\end{abstract}

\section{KARGER}

(C) 2017 S. Karger AG, Basel

E-Mail karger@karger.com

www.karger.com/fpl children with ASD, and the majority (75\%) worked in schools or early childhood settings. SLPs reported that the children's typical age at diagnosis of ASD on their caseload was 3-4 years, completed mostly by a professional team. Conclusions: The results support positive global trends for SLPs using effective practices in assessment and intervention for children with ASD. Two areas where SLPs may need further support are involving parents in assessment practices, and supporting literacy development in children with ASD.

(c) 2017 S. Karger AG, Basel

\section{Introduction}

The median incidence of children with autism spectrum disorder (ASD) reported across countries is estimated as 62 per 10,000, and available data suggest ASD does not appear to be more prevalent in any particular geographic region, socioeconomic, or ethnic group [1]. Defining characteristics of ASD include social and communication difficulties $[2,3]$, and a diagnosis of ASD provides the option of including whether there are comorbid conditions, such as intellectual disability or language im- 
pairment [3]. In a study of 198 preschool children with ASD in Stockholm, researchers found that $78 \%$ of the children exhibited coexisting language impairments, followed by intellectual impairments (49\%), poor motor functioning (37\%), and ADHD (33\%) [4].

The communication difficulties present in children with ASD and the research findings regarding a high incidence of coexisting language disorders suggest that speech-language pathologists (SLPs) are a critical professional group in supporting the diagnosis, assessment, and treatment of children with ASD in their learning and everyday lives. Furthermore, language and communication difficulties have been part of the diagnosis criteria for ASD for several years $[3,5]$. It is surprising, therefore, that relatively little is known about the practices of SLPs internationally in working with children with ASD. A greater understanding of common practices both within and across countries may help identify effective practices that can be shared internationally and provide insights into the work of SLPs in supporting children with ASD that have implications for professional preparation, practice, and policy development. The study reported in this paper sought to address this need through the implementation of an international survey of SLPs' practices in working with children and adolescents with ASD, using the network of SLPs through the International Association of Logopedics and Phoniatrics (IALP).

Previous surveys related to practices in supporting children with ASD have predominantly focused on other professional groups and parents of children with ASD. SLPs may have influenced these practices through collaborative and consultative models of service delivery, but little detail has been provided regarding the SLPs' input. For example, Hess et al. [6] examined the types of interventions and strategies used by public school teachers in the State of Georgia, USA, in supporting children with ASD in their classrooms. The survey reported data from 185 teachers (79\% special educators and $21 \%$ general educators). The data indicated $37 \%$ of the children these teachers were supporting were receiving SLP services, but no further data related to the type of SLP services were reported.

Recently, Plumb and Plexico [7] investigated the preparation of school-based SLPs who worked with children with ASD in the USA through an online survey. The data also provided some insights into the types of interventions and assessment methods used by SLPs. The 401 participants who completed the online survey were practicing in 29 states across the USA. Analyses indicated that more recent graduates were 2.2 times more likely to have

International Survey of SLPs taken courses where topics relevant to working with individuals with ASD were addressed in their professional preparation compared to SLPs who graduated prior to 2006. With reference to their current working practices, most of the respondents (78\%) reported having at least one child with ASD on their current caseload, and most (82\%) had attended continuing education sessions related to supporting children with ASD. Approximately 35\% indicated that they were part of a multidisciplinary team involved in the diagnosis of their clients with ASD; $28 \%$ indicated psychologists and psychiatrists typically diagnosed children with ASD. Most of the respondents reported being confident in assessing and treating the communication skills for a range of social functions of children with ASD, but they had less confidence in assessing and providing interventions for children with ASD in areas related to literacy and academic learning.

A further survey which provides insight into SLP support for children with ASD focused on the setting of SLP services for 854 individuals with ASD in São Paulo, Brazil [8]. The researchers reported that approximately $66 \%$ of the individuals with ASD (mostly children under 12 years of age) had been referred to SLP services for language assessment and intervention. The school setting was the main center for providing SLP services to children, and SLP therapy sessions ranged in frequency from 4 to 16 sessions per month, with an average of 4 therapy sessions per month.

The survey developed for the current study sought to extend previous survey findings through exploring practices of SLPs in diagnosing, assessing, and treating children with ASD from different countries. The questions created in the survey drew upon effective practices reported in the literature. For example, much of the literature regarding assessment of children with ASD suggests that best practice includes comprehensive assessments comprised of social skills, social communication and pragmatics, play, speech, language, sensory modulation, psychological, psychosocial, and academic abilities, and utilizes a team approach due to the multiple and diverse areas of development affected by ASD. Such a team could include, but is not limited to, psychologists, special and general educators, physicians, occupational therapists, as well as SLPs [9]. Questions related to assessment practices in the current study, therefore, explored SLPs' use of these types of assessments and explored whether SLPs are part of a professional team involved in the diagnosis of children with ASD.

The survey also aimed to gather data on common intervention approaches SLPs select when working with 
children and adolescents with ASD. The Autism Evidence-Based Practice Review Group of the Frank Porter Graham Child Development Institute at the University of North Carolina at Chapel Hill, NC, USA, compiled an extensive review of the literature of over 400 articles presenting evidenced-based, focused interventions to individuals with ASD $[10,11]$. The researchers defined focused interventions as practices constructed to focus on a single skill or goal. They distinguished these types of interventions from comprehensive treatment models designed around a conceptual framework that aim to achieve broad learning that impact on the primary challenges of ASD $[10,11]$. The latest analyses from this research group [10] identified 27 focused intervention practices as meeting criteria for evidenced-based practice. They found that most of these practices produced outcomes in children with ASD across multiple development areas. Practices that resulted in positive outcomes across the greatest range of areas were prompting, reinforcement, technology, time delay, and video modelling. Evidence-based practices with outcomes in fewer areas were Picture Exchange Communication System, pivotal response training, exercise, functional behavior assessment, and social skills training. The researchers also noted that technology-aided intervention practices produced positive outcomes across a range of age groups and areas [10, p. 1957]. The questions in the current study were designed to explore the use of evidenced-based intervention strategies SLPs select as well as to gain insight into SLPs' use of commercially available programs.

Gaining insights into SLPs' involvement with children's parents/caregivers and families is another important area for investigation. Hampton and Kaiser's [12] systematic review of interventions that aimed to improve spoken language outcomes in children with ASD highlighted the benefits of parents and clinicians working together in the implementation of intervention strategies. The data suggested that, when intervening early, interventions delivered simultaneously by both a parent and a clinician resulted in greater language gains in the child than interventions implemented by a parent only or a clinician only. Several survey studies have investigated parent's perceptions of services their children with ASD are receiving [e.g., 13, 14] but few have investigated SLPs' practices in involving parents in the assessment and intervention of their children with ASD. Starr and Foy [13] reported that their findings from Canadian parents were remarkably similar to parental survey findings from other countries such as the UK and USA. Comparable findings related to parents' desire for professionals working with their child with ASD were (a) to have frequent communication with them as parents through collaborative ways of working, (b) to be well informed about ASD, (c) to have knowledge of effective interventions, and (d) to have the ability to build positive relationships with their child.

A recent example of a parent survey conducted in Jordan, involving 60 families of children with ASD [15], explored parents' satisfaction with various therapies provided to their child. In this study, speech-language therapy was the most frequent therapy their children were receiving (received by $87 \%$ of the children), followed by occupational therapy (77\%), and physiotherapy (62\%). Overall, parents' satisfaction of services was rated as "average" with higher ratings given to the specialists' knowledge, enthusiasm, and commitment, but lower levels of satisfaction reported for collaboration and communication between parents and specialists. Parents focused on the need for affordable, early intervention services, where services are more integrated, easily accessible, and services that foster strong parent- professional collaborations. Consistent with these findings, a recent government inquiry in New Zealand, into how schools support children with learning needs, including children with ASD [16], highlighted parents' desire for more integrated and accessible services, better communication, and greater consistency in professionals' knowledge and skills in working with their children. The survey developed for the current study includes examining SLPs' reported practices for engaging parents in the assessment and intervention activities for children with ASD. Specifically, the current study aimed to gather data from SLPs across the globe in the following 5 areas:

1. Background information of SLPs working with children with ASD.

2. Characteristics of children with ASD on SLPs' caseloads.

3. Role of SLPs in the diagnosis of ASD.

4. Common assessment practices used by SLPs in working with children with ASD.

5. Common intervention practices for children with ASD including practices in working with parents and other professionals.

\section{Methodology}

The IALP 2016 Child Language Committee (authors) developed the survey questions through an iterative and consultative process over a 6 -month period, taking into account previous survey findings related to supporting children with ASD and evi-
Gillon et al. 
denced-based practices. A final draft survey was piloted with a group of practicing SLPs in the countries represented by the authors. Questions were removed where overlap in information was evident and in response to SLPs' feedback. The final version of the survey comprised 58 questions and was estimated to take 10-12 minutes to complete. The questions were designed with either multiple-choice responses with 5 response categories (never, rarely, sometimes, often, always), short answers with response choices in list format, or open format for responses to be typed into the survey.

The completed English version of the survey was translated into French, Russian, and Portuguese by native speakers of these languages who are SLPs. An IALP committee member who was a bilingual speaker of the native speaker's language and English confirmed that the translated versions were accurate.

The survey was developed online using Qualtrics. Ethical approval was gained from 2 universities, the University of Canterbury in New Zealand and Western Michigan University in the USA. With the support of the IALP Board, the IALP Member Associations of Speech Language Pathology were invited to participate in the online survey. Child Language Committee members followed up with SLP associations to seek their support in distributing the survey link to their members through contacting the SLP association leaders and asking them to distribute invitations to participate in the online survey through their membership communication systems (i.e., association newsletters, websites, email, and facebook communications). Committee members also invited members of online SLP Autism or Child Development special interest groups to participate in the survey through email invitations. No paper-based copies were distributed. The target participants for the survey were SLPs working with children or adolescents with ASD. The first 2 questions of the survey addressed this selection; and if participants responded that they were not SLPs or were not working with children or adolescents with ASD, they were excluded from the survey analyses. The full survey can be found at: http:// ialpdev.info/committees/child-language-committee/.

\section{Survey Participant Information}

The data presented are from 1,114 participants who indicated that they were SLPs and that they worked with children or adolescents with ASD. The participants were from 35 different countries, but 19 countries had fewer than 5 respondents. The countries are listed in Table 1. The respondents were qualified SLPs; and 91\% were experienced in working with children with ASD, with only 9\% indicating that they had recently begun to work with children with ASD. Most of the participants (80\%) had been practicing as an SLP for $>5$ years ( $45 \%$ for $>15$ years). The majority of the participants worked predominantly in schools or early childhood settings, although it was possible for the participants to identify multiple work settings. There were 874 recorded responses to identifying work settings as primary or secondary schools, day care, or preschool settings, 389 responses for private practice, 103 responses for working in ASD-specific centers, and 191 responses for hospital or community health settings. Inspection of comments related to the category "working in other settings" (selected by 144 respondents) showed that this mostly related to SLPs who were working in university clinic settings and the client's home settings. The majority of participants reported working in cities $(80 \%$ of the participants). As much as $75 \%$ of the participants had completed additional specific education in working with children with ASD.
Table 1. Number of respondents by country

\begin{tabular}{lr}
\hline Country & Count \\
\hline USA & 380 \\
Greece & 154 \\
Israel & 101 \\
Australia & 90 \\
Russia & 78 \\
New Zealand & 77 \\
Brazil & 56 \\
Germany & 37 \\
Ireland & 26 \\
Canada & 25 \\
Cyprus & 17 \\
Thailand & 16 \\
Singapore & 12 \\
Italy & 12 \\
UK & 10 \\
India & 5 \\
Others & 18 \\
\hline Total & 1114 \\
\hline
\end{tabular}

Other countries with fewer than 5 respondents: Azerbaijan, Croatia, Egypt, Estonia, Ghana, Hong Kong, Japan, Kazakhstan, Lebanon, Lithuania, Malta, The Netherlands, Norway, Saudi Arabia, Slovenia, South Africa, Taiwan, Ukraine, United Arab Emirates.

The most common area of professional development related to developing children's social communication skills (591 respondents), using alternative communication systems (543 respondents), and learning about parent training strategies (319 respondents).

\section{Results}

The results are reported in 1 of 2 formats: (1) analyses of responses from all participants combined and (2) analyses by country. Analysis by country was undertaken for the 12 countries with the largest numbers of respondents. Descriptive data reported in this article relate to the main findings within each category. More detailed analyses of subsection questions and qualitative analyses of participants' written responses are work in preparation.

\section{Survey Findings Related to Children with ASD on \\ SLPs' Caseloads}

SLPs were asked to identify characteristics of children with ASD on their caseloads within the last 12-month period. The responses indicated that the respondents' caseloads comprised a higher number of: 
Fig. 1. Associated significant conditions for the children with ASD on the speech-language pathologists' caseloads.

Fig. 2. Speech-language pathologists' indication of the typical age at diagnosis of ASD for the children on their caseloads.
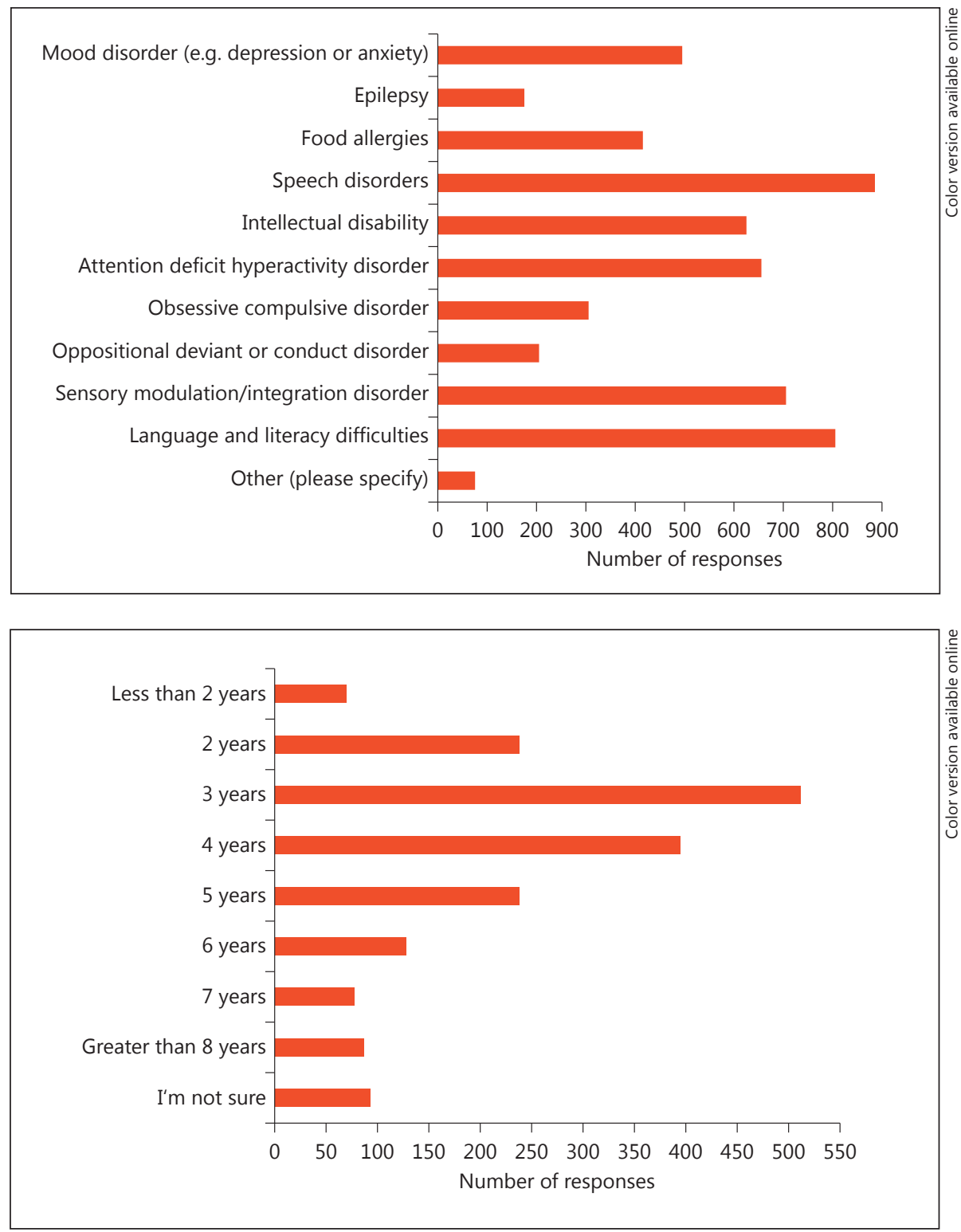

- males (1,035 responses versus 833 responses for females);

- monolingual speakers (848 responses versus 673 responses for multilingual speakers); and

- children from middle socioeconomic backgrounds (905 responses versus 758 responses for low socioeconomic background, and 526 responses for high socioeconomic background).

In addition to speech, language, and literacy difficulties, children with ASD often had other significant conditions (635 responses) as shown in Figure 1. Approximately $60 \%$ of the SLPs indicated that they either sometimes or often work with children who come from a culture different than their own.

\section{Age at Diagnosis of ASD}

Typical age at diagnosis reported for children with ASD on the SLPs' caseload was 3-4 years of age, as shown in Figure 2. Analysis by country was undertaken through analyzing the percentage of responses for each age group for the 12 countries with the largest numbers of respondents. Table 2 shows, for example, that the most frequent response for SLPs from the USA (selected by $30.6 \%$ of the SLPs from the USA) was 3 years of age, followed by 4 years
Gillon et al. 
Table 2. Percentage of SLP responses by country given for the typical age group categories for diagnosis of children with ASD on their caseloads

\begin{tabular}{lcrlrrrrr}
\hline \multirow{2}{*}{$\begin{array}{l}\text { Country } \\
\text { of work }\end{array}$} & \multicolumn{7}{l}{ Typical age of child when diagnosed with ASD } \\
\cline { 2 - 9 } & $<2$ years & 2 years & 3 years & 4 years & 5 years & 6 years & 7 years & $>8$ years \\
\hline USA & 2.8 & 14.6 & 30.6 & 18.8 & 14.6 & 8.3 & 5.6 & 4.9 \\
Greece & 2.3 & 9.2 & 36.4 & 28.9 & 13.3 & 4.6 & 1.7 & 3.5 \\
Israel & 16.8 & 32.1 & 27.6 & 10.2 & 4.1 & 3.6 & 1.0 & 4.6 \\
Australia & 0.7 & 11.7 & 29.0 & 26.2 & 14.5 & 10.3 & 4.8 & 2.8 \\
Russia & 2.6 & 4.3 & 13.2 & 22.6 & 21.7 & 14.9 & 10.6 & 10.2 \\
New Zealand & 0.7 & 10.6 & 37.3 & 31.0 & 10.6 & 3.5 & 3.5 & 2.8 \\
Brazil & 2.5 & 13.2 & 26.4 & 23.9 & 25.2 & 5.0 & 3.8 & 0.0 \\
Germany & 0.0 & 7.1 & 24.7 & 33.1 & 20.8 & 7.1 & 1.9 & 5.2 \\
Canada & 0.0 & 7.7 & 25.6 & 35.9 & 12.8 & 7.7 & 5.1 & 5.1 \\
Ireland & 2.6 & 9.9 & 38.4 & 23.2 & 12.6 & 2.6 & 2.6 & 7.9 \\
Thailand & 7.8 & 12.7 & 23.0 & 23.0 & 10.2 & 5.3 & 5.3 & 12.7 \\
Cyprus & 12.0 & 20.0 & 24.0 & 28.0 & 12.0 & 4.0 & 0.0 & 0.0 \\
\hline
\end{tabular}

Table 3. Professionals responsible for the diagnosis of ASD in children and adolescents ranked in order of frequency

\begin{tabular}{lllllllll}
\hline Countries of work & TP & Psych & P & Ped/Phys & OT & SW & SET & SLP \\
\hline USA & 2 & 1 & 5 & 4 & 7 & 8 & 6 & 3 \\
Greece & 2 & 5 & 1 & 4 & 6 & 8 & 7 & 3 \\
Israel & $2=$ & 1 & $2=$ & 4 & 6 & 7 & 8 & 5 \\
Australia & 3 & 2 & 5 & 1 & 6 & 8 & 7 & 4 \\
Russia & 1 & 4 & 2 & 6 & 8 & 7 & 5 & 3 \\
New Zealand & 2 & 3 & 6 & 1 & 5 & 8 & 7 & 4 \\
Brazil & 6 & $2=$ & 1 & 4 & 5 & $7=$ & $7=$ & $2=$ \\
Germany & 1 & 2 & 4 & 3 & 7 & 8 & 6 & 5 \\
Canada & 3 & 1 & 2 & 4 & 6 & 7 & 8 & 5 \\
Ireland & 2 & 1 & 5 & 6 & 4 & 7 & 8 & 3 \\
Thailand & 3 & $4=$ & 2 & 1 & $4=$ & 8 & 7 & 6 \\
Cyprus & 2 & $4=$ & 1 & 3 & 7 & 8 & 6 & $4=$ \\
\hline All countries combined & 1 & 2 & 5 & 3 & 6 & 8 & 7 & 4 \\
\hline
\end{tabular}

TP, A team of professionals; Psych, psychologist; P, psychiatrist; Ped/Phys, pediatrician/physician; OT, occupational therapist; SW, social worker; SET, special education teacher; SLP, speech-language pathologist. $1=$ most often responsible; 8 = least often responsible; equal sign means that 2 responses were equally ranked.

of age (selected by $18.8 \%$ of the SLPs from the USA). In contrast, the top response from SLPs from Israel (selected by $32.1 \%$ of the SLPs from Israel) was 2 years of age, followed by 3 years of age (selected by 27.6\%), with $<2$ years of age being their third top response (selected by $16.8 \%$ ).

The majority of SLPs (53\%) indicated that SLPs in their region either sometimes or often participated in the diagnosis of children with ASD. Fifteen percent indicated that they were always involved, $25 \%$ indicated that they were rarely or never involved, and 7\% indicated that they were unsure of SLPs' involvement in diagnosis for their region. Table 3 indicates the professionals that the SLPs reported were responsible for the diagnosis in their region. The most common response was "A team of professionals" (571 SLPs selected this category). However, the respondents could select more than one answer, and psychologists and pediatricians were also popular professional categories selected, as shown in Table 3. For those 
Table 4. Tests used in the assessment of ASD for the 12 countries with the highest numbers of participants ranked by assessment usage

\begin{tabular}{|c|c|c|c|c|c|c|c|c|c|c|c|c|c|c|c|c|c|c|c|c|c|c|}
\hline & \multicolumn{22}{|c|}{ Tests used ranked according to popularity } \\
\hline & A & B & $\mathrm{C}$ & $\mathrm{D}$ & $\mathrm{E}$ & $\mathrm{F}$ & G & $\mathrm{H}$ & I & $\mathrm{J}$ & K & $\mathrm{L}$ & M & $\mathrm{N}$ & $\mathrm{O}$ & $\mathrm{P}$ & Q & $\mathrm{R}$ & S & $\mathrm{T}$ & $\mathrm{U}$ & $\mathrm{V}$ \\
\hline Greece & 5 & 3 & 2 & 1 & 7 & 10 & 14 & 6 & 12 & 3 & 20 & 17 & 21 & 14 & 21 & 7 & 7 & 13 & 20 & 20 & 16 & 11 \\
\hline Israel & 19 & 10 & 2 & 1 & 3 & 4 & 12 & 19 & 12 & 7 & 11 & 12 & 19 & 5 & 12 & 6 & 7 & 12 & 19 & 12 & 12 & 7 \\
\hline Australia & 13 & 19 & 19 & 3 & 1 & 15 & 9 & 10 & 19 & 2 & 6 & 17 & 10 & 7 & 16 & 7 & 4 & 10 & 17 & 5 & 19 & 14 \\
\hline Brazil & 2 & 3 & 3 & 7 & 13 & 7 & 13 & 17 & 7 & 17 & 17 & 13 & 17 & 3 & 17 & 1 & 17 & 7 & 6 & 13 & 12 & 7 \\
\hline Germany & 8 & 8 & 8 & 1 & 1 & 3 & 8 & 17 & 3 & 8 & 17 & 17 & 8 & 17 & 17 & 17 & 8 & 3 & 3 & 8 & 3 & 8 \\
\hline Canada & 3 & 11 & 2 & 8 & 1 & 10 & 17 & 6 & 17 & 3 & 15 & 17 & 11 & 5 & 13 & 13 & 8 & 17 & 15 & 8 & 17 & 17 \\
\hline Ireland & 15 & 15 & 15 & 3 & 1 & 5 & 4 & 12 & 15 & 1 & 8 & 15 & 7 & 6 & 12 & 8 & 8 & 8 & 15 & 15 & 15 & 12 \\
\hline Thailand & 12 & 3 & 2 & 12 & 5 & 12 & 5 & 1 & 5 & 12 & 5 & 12 & 5 & 12 & 12 & 12 & 12 & 5 & 5 & 3 & 12 & 12 \\
\hline $\begin{array}{l}1 \text { = ranked first, with } \\
\text { A, Peabody Picture } \\
\text { Vocabulary Test; D, Pres } \\
\text { any version; F, Reynell } \\
\text { Test of Basic Concepts; } \\
\text { (CELF-P); K, Comprehe } \\
\text { man-Fristoe Test of Arti } \\
\text { Language Scales (OWLS } \\
\text { velopment (TOLD); S, T } \\
\text { Educational Planning (A }\end{array}$ & $\begin{array}{l}\text { Tes } \\
\text { sive } \\
\text {; } \mathrm{P}, \mathrm{P} \\
\end{array}$ & $\begin{array}{l}t \text { of } \\
\text { Asse } \\
\text { on (C } \\
\text { ragn }\end{array}$ & $\begin{array}{l}\text { Early } \\
\text { sme } \\
\text { SFTA } \\
\text { hatic }\end{array}$ & Lan & $\begin{array}{l}\text { uag } \\
\text { Spok } \\
\mathrm{Ma} \\
\text { uage }\end{array}$ & kill & Inv & $\mathrm{T}, \mathrm{T}$ & (TH & $\begin{array}{l}\text { D); } \\
\text {; L, } \\
\text { hun } \\
\text { SI); }\end{array}$ & $\begin{array}{l}\text {, Cl } \\
\text { Kauf } \\
\text { cativ } \\
\mathrm{Q}, \mathrm{T}\end{array}$ & $\begin{array}{l}\text { De } \\
\text { st of } \\
\text { La }\end{array}$ & $\begin{array}{l}\text { Eval } \\
\text { Spee } \\
\text { elop } \\
\text { Prob } \\
\text { guag }\end{array}$ & $\begin{array}{l}\text { latio } \\
\text { ch P } \\
\text { nent } \\
\text { em }\end{array}$ & $\begin{array}{l}\text { n of } \\
\text { raxis } \\
\text { Inve } \\
\text { olvir } \\
\end{array}$ & $\begin{array}{l}\text { Lan } \\
\text { Tes } \\
\text { nto } \\
\text { ag }\end{array}$ & $\begin{array}{l}\text { uag } \\
\text { for } \\
\text { es ( } \\
\text { OPS }\end{array}$ & $\begin{array}{l}\text { Fur } \\
\text { hild } \\
\text { DI) } \\
\text {; R, }\end{array}$ & $\begin{array}{l}\text { en }( \\
\text { lam } \\
\text { O, } \\
\text { est }\end{array}$ & $\begin{array}{l}\text { LL); } \\
\text { ntals } \\
\text { SPT } \\
\text { cal a } \\
\text { f Lar }\end{array}$ & $\begin{array}{l}\mathrm{H}, \mathrm{B} \\
\text {-Pres } \\
\text {; M, } \\
\text { nd W } \\
\text { tguag } \\
\text { rume }\end{array}$ & $\begin{array}{l}\text { icture } \\
\text {-4) or } \\
\text { oehm } \\
\text { chool } \\
\text { Gold- } \\
\text { ritten } \\
\text { se De- } \\
\text { nt for }\end{array}$ \\
\hline
\end{tabular}

SLPs who indicated that they were never or rarely involved in the diagnosis of ASD, the most common reason given was that this was not a service offered by their work context ( $n=187$ ) followed by SLPs in their region not being allowed to participate in the diagnosis $(n=117)$.

\section{Assessment Practices}

A total of 852 respondents indicated that they had conducted speech and language assessments of children or adolescents with ASD to plan intervention. The majority of the SLPs (68\%) indicated that they at least sometimes use standardized norm-referenced assessments (such as those that result in scaled scores), to help determine intervention goals for children and adolescents with ASD. Table 4 shows the country analysis of different types of assessments used for the 12 countries with the highest numbers of respondents. The Preschool Language Scales (any version) and the Clinical Evaluation of Language Fundamentals (CELF) (any version) were reported to be commonly used. Criterion-referenced assessments (such
Table 5. Frequency of intervention

\begin{tabular}{lrr}
\hline & \multicolumn{2}{l}{ Responses } \\
\cline { 2 - 3 } & $n$ & $\%$ \\
\hline More than once a week & 350 & 44.87 \\
Once a week & 269 & 34.49 \\
Every 2 weeks & 60 & 7.69 \\
Once a month & 36 & 4.62 \\
Other (please specify) & 65 & 8.33 \\
\hline Total & 780 & 100.00 \\
\hline
\end{tabular}

as questionnaires or checklists) and dynamic assessment methods were reported to be used at least sometimes by 78 and $76 \%$ of the respondents, respectively, to help them determine intervention goals for children and adolescents with ASD.

Areas of children's development that most SLPs reported were commonly assessed (often or always) were receptive and expressive language ( $93 \%$ of the respondents), ear- 
Table 6. Mean rating of frequency of location where SLPs provide intervention on a Likert scale of 1-5

\begin{tabular}{lllllll}
\hline & $\begin{array}{l}\text { Public clinic or } \\
\text { hospital setting }\end{array}$ & $\begin{array}{l}\text { Private } \\
\text { clinic }\end{array}$ & $\begin{array}{l}\text { General } \\
\text { classroom }\end{array}$ & $\begin{array}{l}\text { Special education } \\
\text { classroom }\end{array}$ & $\begin{array}{l}\text { Room outside } \\
\text { classroom }\end{array}$ & $\begin{array}{l}\text { Home } \\
\text { of child }\end{array}$ \\
\hline USA & 1.5 & 1.8 & 2.5 & 3.2 & 3.3 & 1.8 \\
Greece & 1.6 & 3.4 & 2.2 & 2.3 & 2.7 & 2.6 \\
Israel & 2.4 & 3.2 & 1.9 & 3.3 & 3.1 & 1.7 \\
Australia & 1.7 & 2.3 & 2.5 & 2.6 & 2.7 & 2.3 \\
Russia & 1.5 & 1.6 & 1.3 & 1.7 & 2.3 & 2.9 \\
New Zealand & 1.5 & 1.6 & 3.2 & 2.5 & 1.3 & 2.3 \\
Brazil & 2.6 & 4.1 & 1.5 & 1.5 & 2.8 & 1.6 \\
Germany & 1.9 & 1.9 & 1.4 & 1.7 & 2.8 & 1.8 \\
Canada & 2.1 & 2.2 & 1.9 & 2.5 & 2.5 & 2.5 \\
Ireland & 2.6 & 2.5 & 2.4 & 2.9 & 2.5 & 2.3 \\
Thailand & 4.2 & 3.7 & 1.4 & 2.6 & 2.7 \\
Cyprus & 2 & 3.6 & 1.8 & 2.6 & & \\
\hline
\end{tabular}

1 , never; 2 , rarely; 3 , sometimes; 4 , often; 5 , always.

ly social cognitive skills (85\%), conversational skills (85\%), other social cognitive skills (84\%), play behaviors (82\%), parent-child interactions (63\%), and narrative skills (60\%). Less common areas that SLPs often or always assessed were literacy development (43\%), feeding and swallowing (29\%), and sensory motor skills (46\%). Nearly a quarter of all SLPs indicated that they rarely or never assessed literacy development in children with ASD, and almost half of the SLPs who responded to this question indicated they never or rarely assessed feeding or swallowing.

\section{Intervention Practices}

From the total of 1,114 surveys, 780 SLPs responded to the question related to intervention frequency. A qualitative analysis of the comments indicated that some SLPs were not involved directly in intervention for the child but worked in a consultative model with the child's teachers or caregivers. Table 5 indicates the frequency of intervention provided for those who responded to this question. The most common response was more than once a week. Those that selected "other" described their treatment schedule as being adjusted to suit the child's and family's needs, but frequent support such as daily or twice a week was also described. A few SLPs noted that their service only allowed for the SLP to be involved in periodic consultative models of support, such as meeting with teachers or parents, once per every 3 months. Most SLPs reported providing intervention through individual therapy sessions, with $30 \%$ indicating that they always provided individual therapy, and $32 \%$ indicating that they often provided individual therapy. Collectively, the data indicated that individual therapy sessions were likely to be implemented in a room outside the child's general classroom, in a special education classroom, at the child's home, or a private clinic.

Table 6 provides a country analysis of the most frequent locations where SLPs provide intervention. SLPs in some countries (e.g., the USA and Israel) were more likely to provide therapy in a room outside the classroom, where as other SLPs (e.g., New Zealand) were more likely to provide therapy support at the child's home or in the general classroom. SLPs' use of technology (tablets, phones, or computers) in their intervention with children with ASD was evident, with $47 \%$ of the SLPs indicating that they sometimes used technology, and 30\% indicating that they often used technology in their intervention.

Figure 3 and Table 7 illustrate the types of intervention programs used by SLPs. A total of 592 SLPs indicated that they sometimes, often, or always worked on alternative and augmentative (AAC) goals for children with ASD on their caseloads. Figure 3 shows Picture Exchange Communication Systems (PECS) was the most commonly used system reported. Table 7 indicates that for those SLPs who used commercial programs, Applied Behavior Analysis, TEACCH, Hanen, and Floor Time were common programs used. A wide range of programs was reported in the category "others."

\section{Collaborative Practices Working with Parents and Other Professionals}

Most SLPs either always (53\% of the respondents) or often $(22 \%)$ work with parents to enhance their capacity 
Fig. 3. Types of alternative and augmentative communication (AAC) methods used with children and adolescents with ASD.

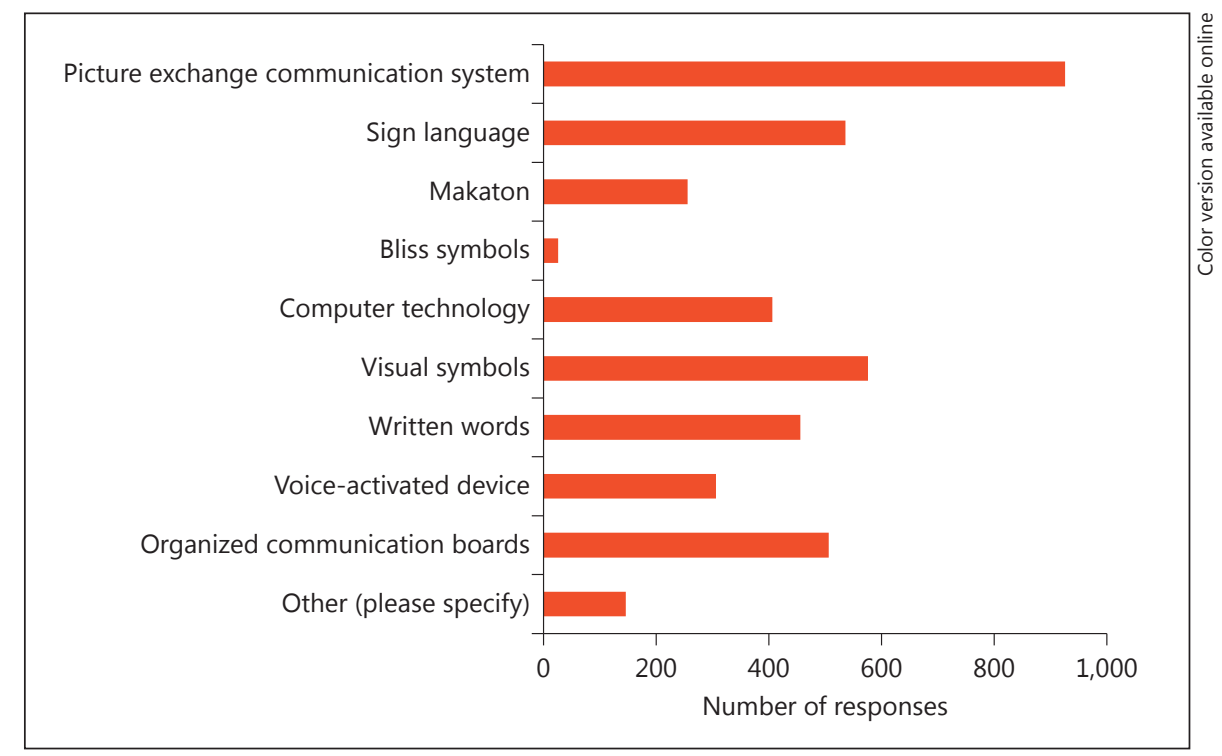

Table 7. Type of commercially available intervention approaches used

\begin{tabular}{ll}
\hline & $\begin{array}{l}\text { Responses, } \\
n\end{array}$ \\
\hline Hanen & 290 \\
TEACCH & 248 \\
Applied Behavior Analysis (ABA) & 239 \\
DIR/Floor Time & 225 \\
Social/Linguistic approach & 208 \\
Intensive interaction & 103 \\
Relationship Development Intervention (RDI) & 64 \\
Parent-Child Interaction Therapy (PCIT) & 59 \\
Pivotal Response Treatment & 43 \\
Denver model & 40 \\
Others & 97 \\
I do not use any commercially available intervention & \\
$\quad$ approaches & 130 \\
\hline
\end{tabular}

to support their children with ASD. More SLPs reported to involve families of children with ASD in setting intervention goals and intervention approaches rather than in assessment practices: $80 \%$ often or always involved families in intervention practices compared to only $39 \%$ who often or always involved parents in assessment practices.

The collaboration with teachers and other professionals was also common with $50 \%$ and $25 \%$ of SLPs recording that they always or often work with teachers in intervention and assessment practices, respectively. Other health professionals, the SLPs were most likely to interact and collaborate with, were occupational therapists (85\%), other SLPs (77\%), psychologists (75\%), and, to a lesser extent, pediatricians (42\%).

\section{Discussion}

To better understand the involvement of SLPs in the diagnosis of children with ASD and their assessment and intervention practices in supporting them, an online survey with 58 questions was developed and distributed to SLPs around the world. The survey distribution was managed online through SLP Associations who were affiliated with the IALP as well as through relevant SLPs' special interest groups.

A total of 1,114 SLPs who currently worked with children with ASD responded to the survey. The data indicated that these were mostly experienced SLPs who predominantly worked with children in educational settings in metropolitan areas. The respondents were from 35 different countries although a number of countries had fewer than 5 participants. The main findings reported in this paper focused on quantitative responses to questions related to SLPs' involvement in the diagnosis of ASD and their assessment and intervention practices.

The SLPs reported that the typical age at diagnosis of ASD was 3 to 4 years of age across most countries; this finding differs from other reports that suggest many children with ASD are not diagnosed until around 5 years of 
age. For example, the median age of American schoolaged children when they were first identified as having ASD was reported as 5 years [17]. Similarly, data from a large data set of Australian children with ASD (over 32,000 children) indicate slightly older ages at diagnosis. Bent et al. [18] examined data collected from helping children with Autism which required a diagnosis of ASD consistent with DSM-IV or DSM-5 $[3,5]$. The average age at diagnosis from 2010 to 2015 was 50 months, with a slight increase in age from 48 to 51 months over time - which also corresponded with an increase in the incidence of ASD between 2010 and 2013. However, the important benefits of early intervention for children with ASD and their families [11, 19] are driving research into understanding the ability to identify ASD in younger children. It is possible that SLPs' caseloads of children with ASD in 2016 reflect approaches that facilitate earlier diagnosis such as multidisciplinary professional teams involved in the diagnosis and identification by pediatricians and psychologists specializing in ASD [19]. In the current survey, Israel was notable for its very early diagnosis of ASD, where SLPs reported that children with ASD on their caseloads were typically diagnosed before 3 years. Possible reasons that may contribute to the young age at diagnosis of children with ASD in Israel are: (a) the monitoring of infant's and children's growth and development from birth to 6 years through family health centers known as "Tipat Halav." This monitoring includes the assessment of children's communication and language development. Consequently, early referral to developmental experts is possible. Importantly, services at all Tipat Halav family health centers are provided at no charge to the family, and regardless of Health Maintenance Organization (HMO) (kupat cholim) membership; (b) child development institutes and units for diagnosing and treating children with developmental problems are spread across the country. Most large cities in Israel have a number of these units. Thus, children who are referred by Tipat Halav for in-depth assessment, diagnosis of any disorder, and treatment are seen relatively quickly; and (c) there is a high awareness among parents, pediatricians, psychologists, and clinicians concerning the importance and benefits of early diagnosis and intervention.

Earlier identification of ASD raises the question of the stability of the diagnosis over time. Daniels et al. [20] analyzed parent questionnaire data from the American Interactive Autism Network (IAN) Research data base for 7,600 children with ASD. Parents were asked if their child's current diagnosis (at mean age 7.6 years $[\mathrm{SD}=$ 3.9]) was different to their child's first diagnosis. Data in-

International Survey of SLPs dicated that $22 \%$ of the sample had a current diagnosis of ASD that differed from their original diagnosis. Children were less likely to have a different diagnosis if they were diagnosed with ASD after 4 years of age. However, there was also less risk of a change in diagnosis when a team of professionals had been involved in the diagnosis. The majority of SLPs in this current survey indicated that a team approach to diagnosis of ASD is common in the regions in which they practice. A number of researchers are recommending screening for autism earlier in life, particularly for babies who may be at higher risk (e.g. for preterm babies, see Darcy-Mahoney et al. [21]); and SLPs involvement in ASD screening procedures for early signs of communication difficulties warrants further investigation.

Consistent with understanding the importance of communication and social development, most SLPs reported to contribute to the diagnosis of ASD. However, a small group (approximately 10\%) indicated that SLPs were "not allowed" to participate in the diagnosis in their region of work. Data from this study suggest that such practices are contrary to the work of SLPs internationally and also contrary to research highlighting the benefits of a team approach to diagnosis.

Best practices in the assessment of children with ASD highlight the need for a comprehensive assessment approach, utilizing both formal and informal assessment measures, addressing areas known to be common to ASD, such as communication, social and pragmatic language skills as well as assessment to identify co-existing conditions [9].

The quantitative data obtained in this survey suggest that the majority of SLPs around the world who have recently engaged in the assessment of children with ASD undertake comprehensive assessments of children's communication abilities using a range of assessment measures and methodologies. Areas critical to spoken language development and social communication abilities appear to be routinely assessed by most SLPs who participated in this survey. Qualitative analyses of informal assessment measures SLPs recorded (work in preparation) will provide further insight into their assessment practices. One area that currently appears to be less commonly assessed is children's literacy development. This was surprising, given that most respondents were working in educational settings, and the scope of practices for SLPs have long included written language assessment and intervention [e.g., 22]. Further, the co-existence of language and literacy difficulties in children with ASD on the SLPs' caseloads was reported as high. Our survey data are consistent with Plumb and Plexico's [7] findings, indicat- 
ing that SLPs are less confident in assessing aspects of children's written language development. Previous studies have suggested that although there is considerable variability in the reading profiles of children with ASD, reading comprehension difficulties can be common [23$25]$. Further research in understanding early literacy development in children with ASD $[26,27]$ may help clarify the types of assessment and interventions that would be useful for SLPs to implement in children with ASD. This may also be an area of potential professional development need for SLPs as well as an area to enhance in professional preparation programs for SLPs. The benefits of SLPs being more actively involved in written language assessment, including early literacy skill development of children with ASD, warrant further research investigation.

Another area for continued investigation is the SLPs' collaborative practices with children's parents in the assessment process. Surveys of parents of children with ASD have highlighted their desire for more direct involvement and clear communication in all aspects of the management of their children [13]. Data from this survey indicated that the SLPs are less likely to involve parents in the selection of assessments and assessment settings than in interventions. However, most SLPs reported involving parents in intervention activities, and the Hanen intervention approach (which includes parent training modules) was the most commonly selected commercially available intervention approach. Further, nearly $1 / 3$ of the participants reported engaging in professional development related to learning about parent engagement strategies or programs. This finding is noteworthy given a recent meta-analysis of intervention effectiveness to improve spoken language development in young children with ASD highlighted the benefits of parental involvement [12]. The researchers analyzed spoken language outcomes of 26 studies involving children with ASD under 8 years, and reported larger treatment effects where both the parent and the clinician were involved in intervention implementation.

Our data revealed that the majority of SLPs reported working with children from a different cultural background than their own. Although not explored in this survey, understanding how SLPs are providing culturally responsive assessment and interventions to meet the needs of culturally diverse groups of children with ASD is an area for future research. Gillon and Macfarlane [28] provide a discussion of culturally responsive frameworks and an example of a collaborative approach between SLPs, teachers, parents, and others in facilitating young children's phonological awareness development to encourage early literacy success.
Another interesting finding related to the SLPs' caseloads was the relatively high number of females with ASD (although still lower than the number of males). Prevalence studies indicate variability in the ratio of males to females with ASD, but typically demonstrate a much higher incidence of males with ASD compared to females. Although the survey data do not provide information on the number of males and number of females on an individual SLP's caseload, it would be interesting to explore this in further studies and to examine the referral process for providing SLP services to children with ASD.

Evidence that SLPs around the world are frequently engaged in research-informed practices, are collaborating and consulting with teachers, parents, other SLPs, and health professionals, are providing support in relatively intensive intervention schedules, and are embracing new technologies in their intervention practices is encouraging. In regions or employment situations where this may not be the case (e.g., where resources for SLP services are limited or where an SLP's choice to offer research-informed approaches to meet the child's and family's need is restricted), advocacy to model improved service delivery on these global positive trends in intervention may be warranted.

\section{Limitations}

The findings are limited by the small number of respondents relative to the number of SLPs working with children and adolescents in the countries of the survey participants. It was apparent that a higher number of survey respondents came from countries with members of the IALP Child Language Committee: USA, New Zealand, Australia, Greece, Israel, Russia, Canada, Cyprus, and Brazil. Although all IALP member associations were invited to participate, the influence of the committee members within their own organizations to recruit participants was evident. Considering how to gain a more even distribution of respondents across countries would be important for future international surveys of SLPs.

The descriptions of quantitative data collected from "forced-choice" questions (with predefined answers, i.e., never, rarely, sometimes, often, always) or from lists of items provided are useful in identifying common practices, but they are limited in their ability to capture more individualized or emerging practices. Qualitative analyses of the participants' written responses and comments provided in the survey will be important to support the quantitative data presented. Overall though, the quantitative data collected from the 1,114 SLPs from around the world is encouraging in that many effective practices in
18

Folia Phoniatr Logop 2017;69:8-19 DOI: $10.1159 / 000479063$
Gillon et al. 
supporting communication skill development in children with ASD appear to be commonly implemented across regions and services.

\section{Acknowledgements}

The authors would like to thank the SLPs who participated in the survey and to acknowledge the support of the IALP Board members and Speech-Language Pathology Associations for the distribution of the survey to their members. The authors would also like to acknowledge speech-language pathologists Dr. Leanne Wilson and Dr. Amy Scott and educationists Dr. Amir Sadeghi and
Dr. John Boereboom (Director of Curriculum Evaluation and Monitoring Centre) from the College of Education, Health and Human Development at the University of Canterbury, New Zealand, for technical support in the survey design and analyses. The authors are grateful to the New Zealand Ministry of Education Business Innovation and Employment for financial assistance through the Better Start National Science Challenge, Research grant No. UoC - 15-02688.

\section{Disclosure Statement}

The authors have no financial or nonfinancial conflicts of interest in the publication of these data.

\section{References}

1 Elsabbagh M, Divan G, Koh YJ, Kim YS, Kauchali S, Marcin C, Montiel-Nava C, Patel V, Paula CS, Wang C, Yasamy MT, Fombonne E: Global prevalence of autism and other pervasive developmental disorders. Autism Res 2012;5:160-179.

2 Levy SE, Schultz RT: Autism. Lancet 2009; 374:1627-1638.

3 American Psychiatric Association: Diagnostic and Statistical Manual of Mental Disorders, ed 5 (DSM-5). Washington, American Psychological Association, 2013.

-4 Carlsson LH, Norrelgen F, Kjellmer L, Westerlund J, Gillberg C, Fernell E: Coexisting disorders and problems in preschool children with autism spectrum disorders. ScientificWorldJournal 2013;2013:213979.

5 American Psychiatric Association: Diagnostic and Statistical Manual of Mental Disorders, ed 4 (DSM-IV tr). Washington, American Psychological Association, 2008.

-6 Hess KL, Morrier MJ, Heflin LJ, Ivey ML: Autism treatment survey: services received by children with autism spectrum disorders in public school classrooms. J Autism Dev Disord 2008;38:961-971.

7 Plumb AM, Plexico LW: Autism spectrum disorders: experience, training, and confidence levels of school-based speech-language pathologists. Lang Speech Hear Serv Sch 2013; 44:89-104.

8 Defense-Netrval DA, Fernandes FDM: Availability of speech-language therapy to individuals with ASD. Autism Open Access 2013;3: 117.

9 Wilkinson L: A Best Practice Guide to Assessment and Intervention for Autism Spectrum Disorder in Schools, ed 2. Philadelphia, Jessica Kingsley Publishers, 2016.

10 Wong C, Odom SL, Hume KA, Cox AW, Fettig A, Kucharczyk S, Schultz TR: Evidencebased practices for children, youth, and young adults with autism spectrum disorder: a comprehensive review. J Autism Dev Disord 2015; 45:1951-1966.
11 Odom SL, Collet-Klingenberg L, Rogers S, Hatton D: Evidence-based practices for children and youth with autism spectrum disorders. Preventing School Failure 2010;54:275282.

12 Hampton L, Kaiser A: Intervention effects on spoken-language outcomes for children with autism: a systematic review and meta-analysis. J Intellect Disabil Res 2016;60:444-463.

13 Starr EM, Foy JB: In parents' voices: the education of children with autism spectrum disorders. Remedial Spec Educ 2012;33:207216.

14 Balestro JI, de la Higuera A, Cibelle A, Sugawara V, Gibello I, Segeren L, Fernandes FDM: Relations between the perception of communication difficulties, stress levels and behavior of children with Autism Spectrum Disorders. Psychology 2016;7:1391-1396.

15 Jabery MAA, Arabiat DH, Khamra HAA, Betawi IA, Jabbar SKA: Parental perceptions of services provided for children with autism in Jordan. J Child Fam Stud 2014;23: 475-486.

16 Yang J: Inquiry into the identification and support for students with the significant challenges of dyslexia, dyspraxia, and autism spectrum disorders in primary and secondary schools. Report of the Education and Science Committee. Presented to the House of Representatives (New Zealand Parliament) November, 2016.

-17 Pringle B, Colpe LJ, Blumberg J, Avila RM, Kogan MD: Diagnostic history and treatment of school-aged children with autism spectrum disorder and special health care needs. NCHS Data Brief 97, Hyattsville, National Center for Health Statistics, 2012.

18 Bent CA, Josephine B, Dissanayake BC: Change in autism diagnoses prior to and following the introduction of DSM-5. J Autism Dev Disord 2017;47:163-171.

19 Fernandes FDM, Amato CAH, DefenseNetrval DA, Molini-Avejonas DR: Speechlanguage intervention for children with $\mathrm{Au}$ - tism Spectrum Disorder in Brazil. Top Lang Disord 2014;34:155-167.

20 Daniels AM, Rosenberg RE, Law JK, Lord C, Kaufmann WE, Law PA: Stability of initial Autism Spectrum Disorder diagnoses in community settings. J Autism Dev Disord 2011; 41:110-121.

21 Darcy-Mahoney A, Minter B, Higgins M, Guo Y, Williams B, Head Zauche LM, Birth K: Probability of an autism diagnosis by gestational age. Newborn Infant Nurs Rev 2016; 16:322-326.

22 American Speech-Language-Hearing Association (ASHA): Scope of Practices in SpeechLanguage Pathology 2007. Available at: http:// www.asha.org/policy.

23 Nation K, Clarke P, Wright B, Williams C: Patterns of reading ability in children with Autism Spectrum Disorder. J Autism Dev Disord 2006;36:911-919.

24 Fernandes FDM, de La Higuera A, Cibelle A, Cardoso C, Navas ALGP, Molini-Aveionas DR: Reading in autism spectrum disorders: a literature review. Folia Phoniatr Logop 2015; 67:169-177.

25 Senokossoff GW: Developing reading comprehension skills in high-functioning children with Autism Spectrum Disorder: a review of the research, 1990-2012. Read Writ Q 2016;32:223-246.

26 Asaro-Saddler K: Writing instruction and self-regulation for students with Autism Spectrum Disorders: a systematic review of the literature. Top Lang Disers 2016;36:266283

27 Westerveld MF, Paynter J, Trembath D, Webster AA, Hodge AM, Roberts J: The emergent literacy skills of preschool children with autism spectrum disorder. J Autism Dev Disord 2017;47:424-438.

28 Gillon G, Macfarlane A: A culturally responsive framework for enhancing phonological awareness development in children with speech and language impairment. Speech Lang Hear 2017;20:163-173. 